\title{
Water resource vulnerability: simulation and optimisation models
}

Lan Hoang PhD, MSc, BSC

Centre for Sustainable Development, Department of Engineering, University of Cambridge, Cambridge, UK
Suraje Dessai PhD, BSC

Sustainability Research Institute and ESRC Centre for Climate Change Economics and Policy, School of Earth and Environment, University of Leeds, Leeds, UK (corresponding author: s.dessai@leeds.ac.uk)

Approaches to adaptation to a changing climate in water resource planning have relied on both simulation and optimisation models. Simulation models project the impacts of climate change on water system performance, while optimisation models show the optimal system performance under climate change conditions. This study uses two water resource models to analyse a water resource system in Sussex (south-east England) under climatic and socioeconomic uncertainty. Overall, the simulation and optimisation models show structural model uncertainty. The simulation model highlights potential vulnerability in current operational practice, while the optimisation model shows that the current system could be vulnerable to climate change and demand growth even under the best-case scenario. The integrated scenarios in this study combine both climate scenarios from four different climate products over the periods of 2020s, 2030s and 2050s and socio-economic scenarios represented by different demand profiles. The results show that water demand quickly becomes a controlling factor once it increases by more than $35 \%$ from the 2007 baseline level. Both models demonstrate a gradual increasing risk of supply deficit in the 2020s and the 2030s. Water deficit risks vary widely in the 2050s and are highly dependent on the socio-economic scenarios.

\section{Introduction}

Under the pressure of population growth and climate change impacts, water resource vulnerability has manifested across scales and locations (Alcamo and Henrichs, 2002; Gan, 2000; Jain et al., 2002; Oki and Kanae, 2006). At the global scale, Vörösmarty et al. (2000) have used the water balance model to show a significant increase of vulnerability to water scarcity by the 2020 s. Similarly, Arnell (1999) showed an increasing vulnerability of global water resources from the 2020s to the 2030s. However, his analysis for the 2050s also highlighted that different versions of the same model produce inconsistent projections of whether water stress would reduce or increase (Arnell, 1999). On a local scale, Fowler et al. (2003) showed that water resources in Yorkshire, England, would likely be vulnerable to severe drought events by the 2080s, while Lopez et al. (2009) demonstrated high vulnerability of water resources in south-west England by using 246 simulations from a larger perturbed physics ensemble of one climate model.

As such, adaptation to a changing climate has become a pressing need for planning of water resources. Traditionally, water planners and managers often utilise simulation and optimisation models to explore system performance under multiple options and select the best possible option (Loucks and Van Beek, 2005). In adaptation studies, simulation and optimisation models have been used in applications, as done by Kasprzyk et al. (2013) and Matrosov et al. (2013a, 2013b). Simulation models generate system performance under a set of conditions, while optimisation models seek to find operation that gives rise to the best available system performance under such conditions. The former approach offers a comparative analysis of available options, while the latter provides a speedy assessment of the best available option according to the decision-makers' criteria.

This paper focuses on the potential implications of modelling choices on the assessment of vulnerability in a water resource system. In particular, this study questions whether such choices may highlight different vulnerabilities of the water resources system and, therefore, lead to different emphases of adaptation decisions. The study uses a case study in Sussex, south-east England, as an example. Section 2 describes the methodology used in the vulnerability assessment, including the incorporation of the uncertainty factors and the water resource models. Section 3 presents the results and a discussion of the results. Section 4 then summarises the key vulnerabilities of the Sussex water resource system to uncertainty.

\section{Methodology}

\subsection{The study area}

The study area is in Sussex in south-east England (Figure 1), a region under great pressure to adapt to population growth and climate change. These two elements have become two major new challenges for the area, with $15 \%$ of its water resource zones 


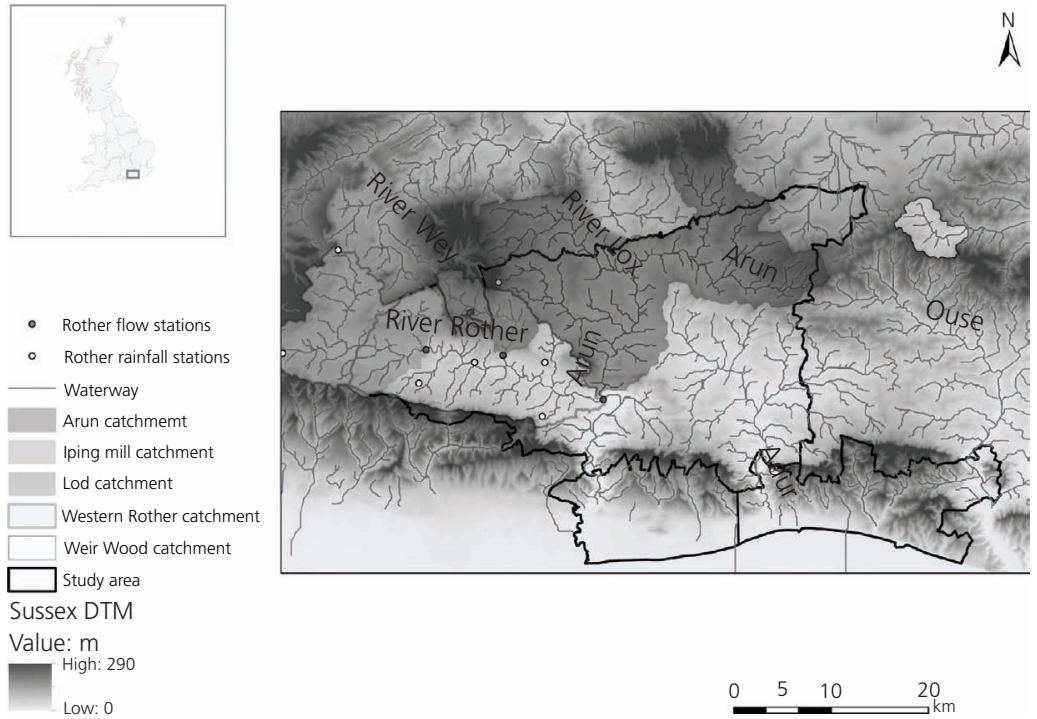

Figure 1. Map of the study area. Data courtesy of the Ordinance Survey, Centre for Ecology and Hydrology, Wallingford, and British Geological Survey 2012

seriously water stressed (Cave, 2009). Climate change, a deep uncertainty in planning, is also a big driver of changes in the water supplies (Arnell and Charlton, 2009).

The area is divided into three subareas: North Sussex, Worthing and Brighton. North Sussex is drained by the tributaries of the Rother (often called the Western Rother to distinguish from the River Rother in East Sussex), the Adur and the Arun. Among these rivers, the Rother and the Arun constitute important water resources for North Sussex. Meanwhile, water resources in Worthing and Brighton mainly rely on groundwater. Geologically, the whole study area overlays the Chalk and the Greensand aquifers, which produce moderate to high groundwater yield. The water supply of the area relies on the Rother, the Arun and various groundwater boreholes in the Worthing and Brighton areas. The water resources of the area are managed by Southern Water Services Ltd, a private company of Greensand Investments Limited. This water company originates from Southern Water Authority, a pre-1989 public water authority, and still retains various management practices and facilities of its predecessor.

\subsection{The scenarios}

Scenarios, as descriptions of potential future conditions, can help inform decision-making under uncertainty. Uncertainty can stem from either socio-economic and biophysical factors or often from both (Parson et al., 2007; Weaver et al., 2013). Scenarios can therefore be categorised into main uncertainty or influencing factors, such as climate scenarios and socio-economic scenarios (Downing et al., 2003). The integrated scenarios in this study combine both types, including climate scenarios from four different climate products over the periods of 2020s, 2030s and 2050s and socio-economic scenarios represented by different demand profiles.

\subsubsection{Climate and streamflow scenarios}

In this study, climate scenarios from four climate products are used (Table 1). As the table illustrates, two climate products are altered observations using projected change factors and the other two are modelled data of the future periods. The chosen emission scenario is the Medium Emission Scenario. The CATCHment MODel (Catchmod) used in this study is a water balance model that has been used by the UK Environment Agency (EA) for various catchments. The model uses six key parameters, which are explained in detail by Wilby and Harris (2006). In essence, the model divides the study area into various contributing zones. Model parameters are the area of the zones, direct percolation (the fraction of precipitation infiltrating pass the soil horizon, potential drying constant), gradient of the drying curve, linear storage constant and non-linear storage constant. This study uses the Catchmod set of parameters used in the water company's 2009 Water Resource Plan. The chosen climate projections for the study area are based on the results of the Hadley Centre Regional Climate Model HadRM3 (hereby termed the RCM). Other climate projections used in the study include 10000 Change Factors of the 2009 UK Climate Projections (UKCP09), the 11 Spatially Coherent Projections (SCPs) of UKCP09 and the Future Flows (FF) downscaled data from the 11 HadRM3 runs. They are all valid sources of climate information and have been applied in various impact and adaptation studies (Bell et al., 2012; Wade et al., 2013). The UKCP09 10000 Change Factors are based on a complex methodology that includes the 11 HadRM3 simulations, many simulations of the Hadley Centre global climate model (GCM), other GCMs and a Bayesian emulator (Murphy et al., 2010). The UKCP09 product adopts a probabilistic approach to represent climate change projections; this approach encapsulates a larger range of results than in previous climate scenarios and 


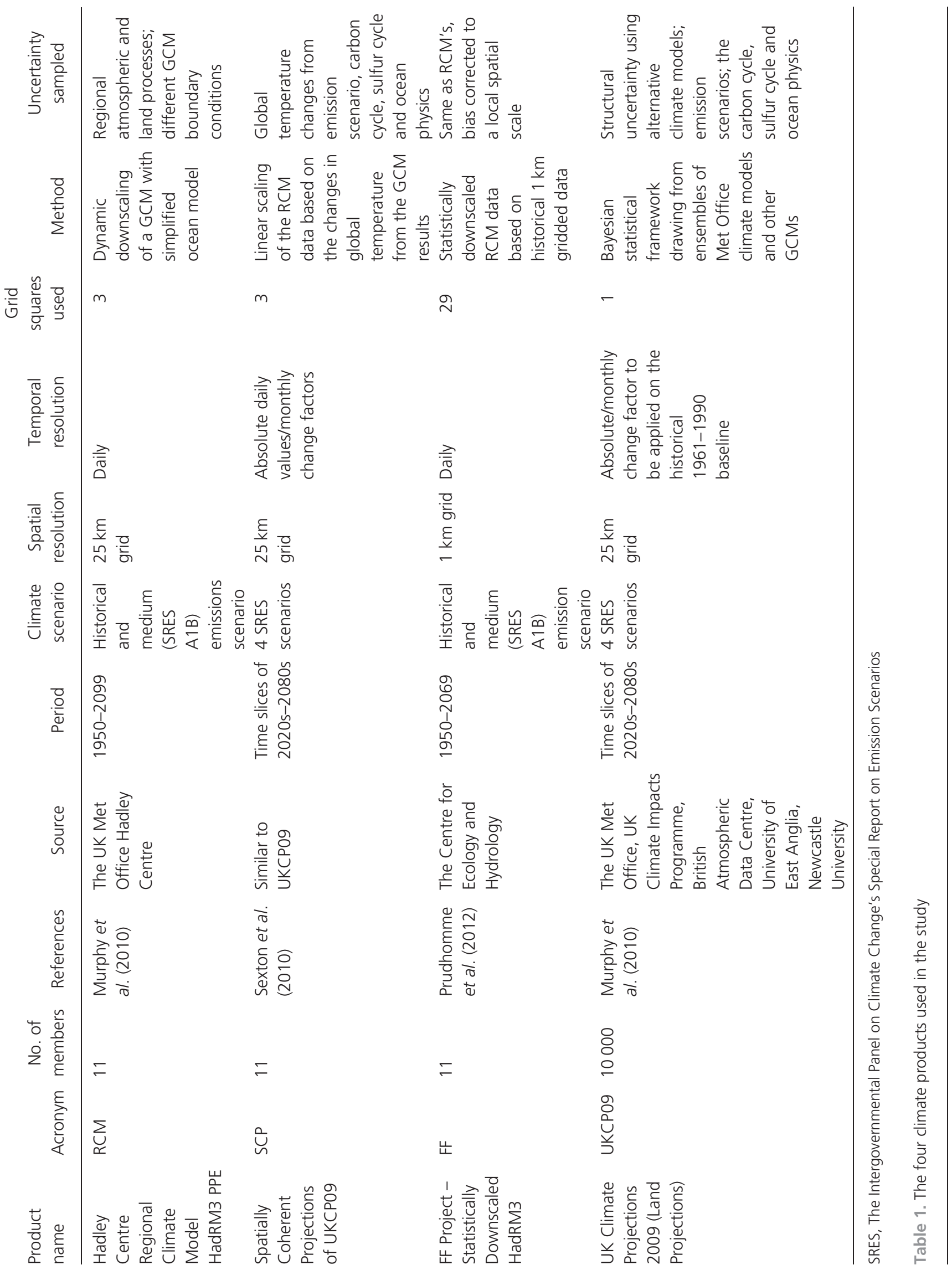


enables the quantification of uncertainty. Yet these projections have received criticism for the lack of interannual variability and spatial correlation among the grids (Chun et al., 2013). By contrast, the 11 runs of the HadRM3 are spatially coherent and include temporal variability but lack the probabilistic ranges of UKCP09. Furthermore, the RCM runs might require bias correction before being used for hydrological models. Based on the original RCM data and historical gridded rainfall data, the FF project had bias correction and further downscaled the RCM data. These two sets of outputs thus also have different spatial resolutions, with the UKCP09 grids being $25 \mathrm{~km} \times 25 \mathrm{~km}$ and the FF grids being $1 \mathrm{~km} \times 1 \mathrm{~km}$. The streamflow scenarios were generated from the hydrological model Catchmod (Wilby, 2005) using rainfall and potential evapotranspiration (PET), the latter being calculated using the temperature-based Oudin equation (Oudin et al., 2005).

\subsubsection{Socio-economic scenarios}

The focus of this study and the models used is on domestic water supply and therefore does not include industrial water use. Household water demand projections in the 2020s and the 2030s were based on Southern Water's projections from their 2009 Water Resource Management Plan. In this plan, Southern Water extrapolates the average and peak demands for the period 2009-2034, thus covering part of the 2020s and 2030s periods (Southern Water, 2009). The average dry year demands in 2024 and 2034 were selected to act as a representative demand for the 2020 s and the 2030s, particularly during dry periods. The daily pattern of the demand profile was based on the estimated 1995 water demand and linearly scaled to produce the 2020s, 2030s and four 2050s demand profiles. The projected annual demand in 2007-2034, which covers the 2020 s and 2030 s periods, was prepared by Southern Water based on assumptions on population growth, household number, metering proportion, metering effect and per capita consumption. At the time of the study, projections from the water company for the 2050s were not available. Therefore, the figures used figures were from the 2050s Foresight Water Scenarios, which project changes in total water demand based on factors such as per capita consumption, population and household.

For the 2050s, this study used the EA 2050 scenarios (EA, 2008). The 2007 annual water demand was used to produce the four 2050s demand profiles under the corresponding socio-economic scenarios described by the EA scenarios, which use a 2006/2007 baseline. While the 2020s and 2030s Southern Water's projections are based on extrapolated water demand, the Foresight Scenarios by the EA (Berkhout and Hertin, 2002; SPRU, 2002) provide a more general assessment of societal trend in the future, including water demand. These scenarios describe alternative socioeconomic states of future society based on a spectrum of consumers' and policymakers' choices. They reflect the potential varying degrees of sustainability awareness in governance - that is, sustainability against short-term socio-economic concerns. The scenarios were named Sustainable Behaviour, Innovation, Local Resilience and Market Forces. Each of these scenarios reflects a different mode of governance and consumption (EA, 2008). In essence, the projected changes are as follows.

- Innovation: The total demand reduces by $4 \%$, the water per capita consumption (pcc) is $125(1 / \mathrm{d}) /$ capita and the population grows by $35 \%$. The responsibility to find adaptation strategies lies with the government and scientists; demand reduction is due to sustainability-led governance and technological innovation.

- Market Forces: The total demand increases by 35\%, the pcc is $165(1 / \mathrm{d}) /$ capita and the population grows by $45 \%$. Water demand is driven by the market trend, focusing on cost optimisation and growth.

- Local Resilience: The total demand increases by $8 \%$, the pcc is $140(1 / d) /$ capita and the population grows by $25 \%$. People realise the need for demand reduction and take actions towards it. Their efforts, however, are moderate due to the low priority of demand saving and the lack of incentives from the government.

- Sustainable Behaviour: The total demand declines by $15 \%$ due to proactive demand reduction from individuals; the pcc is $110(\mathrm{l} / \mathrm{d}) /$ capita, and the population grows by $20 \%$.

\subsection{Water resources models of the current Sussex area}

The Sussex area has been modelled by a simulation model (Wade, 2005) and an optimisation model (Atkins, 2009). These models are designed for different purposes. The former model was used to study the deployable output of the area given changes in flows of the Rother River and domestic water demand. The latter was used for the recent water resources management plan to analyse the area's water shortage and appraise planning options. They have both been used for water resources planning in the area. Given the different structures of these models, the study uses these models to explore whether model choices may highlight different vulnerabilities of the water resources system. Such differences, arising from using different model structures to characterise the study area, are classified as structural uncertainty (Beven, 2009). The study preserves the details of each model, such that the optimisation model has more details of the Sussex water delivery network than the simulation model does. This study uses three models to demonstrate model structural uncertainty on vulnerability analysis as follows.

- The reference model: The reference model in this study is the water resource model used by the water company and their consultancy company. They used Aquator, a water resource software application by Oxford Scientific Software Ltd. This model was constructed by Atkins Ltd for Southern Water's Water Resource Management Plan 2009 and other planning reports.

- The Visual Basic .Net (VB.Net) simulation model: This model was coded in VB.Net based on an Excel-based model by Wade (2005). The model shows demand-supply interactions of North Sussex, which consists of the River Rother, Weirwood and Hardham groundwater and other groundwater 
sources and transfer to and from other water companies (South East Water and Portsmouth Water). The model can use time series for groundwater sources and demand profiles. These regional demands were constructed by summing the relevant individual demand profiles of the Aquator model. Like the Aquator model, the groundwater nodes are subject to daily and annual licenses. In this study the model uses these licenses to determine available groundwater abstraction, such that water can be withdrawn from the groundwater sources until reaching the maximum amount permitted by the daily and annual licences. This model simplifies the Aquator model to the scale of water resource zones, with each zone consisting of major proxy nodes instead of individual Aquator nodes.

- The Generalised Algebraic Modelling Software (Gams) optimisation model: This model was coded in Gams based on a summary note of the Aquator model. The model simplifies the Aquator model but retains more details than the simulation model. The optimisation model additionally includes the Worthing and Brighton areas, but the deficits of each region are still separated and therefore can be compared to those of the simulation model. Compared to the simulation model, the optimisation model has more detailed modelling of the water flows, including the transfer capacity in each link. Each scenario requires three model runs. For each scenario, the model first minimises total deficits in environmental flows; it then minimises the supply deficits while maintaining environmental deficit at that minimum level. Finally, the model minimises the operational cost of pumping and delivering water supply. This cost was based on model specification of the Aquator model, with slight alteration to reflect the supplying priority of the source nodes. Compared to the simulation model, the optimisation model has a more detailed network configuration. In this model and the Aquator model, the Weirwood reservoir can supply only for part of the network instead of the whole Sussex demand as in the simulation model.

Table 2 presents the main differences of the three models. The reference Aquator model is the most complex model but with the longest running time. On the other hand, the simulation model and the optimisation model have a shorter running time due to their simplified network version and simpler visual interface compared to the reference model. The reference has a detailed network structure, with transfer constraints on many links, particularly in the Worthing and Brighton areas. Meanwhile, the optimisation model

\begin{tabular}{|c|c|c|c|}
\hline & Reference model & Simulation model & Optimisation model \\
\hline $\begin{array}{l}\text { Software } \\
\text { description }\end{array}$ & $\begin{array}{l}\text { Commercial software used } \\
\text { by water companies and } \\
\text { other consultancy } \\
\text { companies in water } \\
\text { resource planning } \\
\text { Has a GUI }\end{array}$ & $\begin{array}{l}\text { VB.Net program coded by } \\
\text { Lan Hoang based on Wade } \\
\text { (2005) } \\
\text { Has a simple GUI, very little } \\
\text { visualisation }\end{array}$ & $\begin{array}{l}\text { Gams program coded by the } \\
\text { lead author based on the } \\
\text { Aquator Sussex model } \\
\text { Can be used for other model } \\
\text { network by changing the input } \\
\text { files } \\
\text { No GUI, linked to a Python } \\
\text { visualisation tool }\end{array}$ \\
\hline Timescale & Daily & Daily & Weekly \\
\hline Spatial scale & $\begin{array}{l}\text { Includes North Sussex, } \\
\text { Worthing and Brighton }\end{array}$ & $\begin{array}{l}\text { Includes North Sussex, Worthing } \\
\text { and Brighton }\end{array}$ & $\begin{array}{l}\text { Includes North Sussex, Worthing and } \\
\text { Brighton }\end{array}$ \\
\hline Spatial resolution & $\begin{array}{l}\text { Individual supply and demand } \\
\text { nodes within each region }\end{array}$ & Regional demands & $\begin{array}{l}\text { Simplified nodes from Aquator } \\
\text { network }\end{array}$ \\
\hline Calculation mode & Optimisation/simulation & Simulation & Optimisation \\
\hline $\begin{array}{l}\text { Annual } \\
\text { groundwater } \\
\text { licenses }\end{array}$ & Yes - individual nodes & Yes - regional nodes & $\begin{array}{l}\text { Yes - regional nodes but finer scale } \\
\text { than those of the simulation model }\end{array}$ \\
\hline $\begin{array}{l}\text { Reservoir control } \\
\text { curve }\end{array}$ & Yes - partially implemented & No & $\begin{array}{l}\text { Yes - can be partially or fully } \\
\text { implemented }\end{array}$ \\
\hline Demand profile & $\begin{array}{l}\text { Modified } 1995 \text { regional } \\
\text { demand profile downscaled to } \\
\text { the node level }\end{array}$ & $\begin{array}{l}\text { Modified } 1995 \text { regional demand } \\
\text { profile at the water resource zone } \\
\text { level }\end{array}$ & $\begin{array}{l}\text { Modified } 1995 \text { regional demand } \\
\text { profile at the sub-water resource } \\
\text { zone level }\end{array}$ \\
\hline Running time & $\sim 30$ min per run & 15 s per run & $\sim 2$ min per run \\
\hline
\end{tabular}

GUI, guided user interface

Table 2. Comparison of the three water resource models 
Engineering Sustainability

Volume 170 Issue ES4
Water resource vulnerability: simulation

and optimisation models

Hoang and Dessai and the simulation model implement transfer constraints at the regional level - for example the link between North Sussex and Worthing. Additionally, the optimisation retains more details of North Sussex and Brighton than the simulation model. Yet the optimisation model runs on a weekly time step, while the reference model and the simulation model use a daily time step. Model uncertainty due to different model structures and algorithms was analysed using a 1888-2005 reference input data. The input data for the future climate contain the full set (11 members) RCM, FF and SCP and a sampled set of UKCP09 data (100 for the optimisation model and 1000 for the simulation model) for each of the time periods 2020s, 2030s and 2050s. Socio-economic scenarios in the model consist of one universal scenario for the 2020s and 2030s and four EA scenarios for the 2050s, as described in Section 2.2.2. The vulnerability of the study area to droughts was subsequently analysed through the simulation and the optimisation models using climate and socio-economic scenarios.

\section{Results and discussion}

\subsection{Model evaluation against the reference model}

This section compares the performances of the three models based on the state of the Weirwood reservoir from 1888 to 2005 . For less severe events, the simulation model tends to be more conservative and empties the reservoir less than the reference model. The reference model mimics hosepipe bans, which reduce water demand every time the Rother flows are below the 90th percentile of the Rother curve (the mean daily flows during the 1961-1990 period), and therefore reduces demand pressure on Weirwood. The Weirwood reservoir also follows a control curve, which shows the minimum storage before the reservoir can release water. An example of a control curve is shown in Figure 2. If the control curve is applied when the Rother flows are higher than the recession curve, the Weirwood time series of the optimisation model become close to those of the reference model, in particular during the 1921/1922 drought (Figure 3). The optimisation model still exhibits a slight tendency to not take the full inflows, due to its optimisation mode, which aims to reduce the total duration of water deficits within the whole period.

The simulation model appears to perform reasonably well compared to the reference model if the state of Weirwood Reservoir is used as an indicator. To characterise the correlation, firstly, this study uses the Spearman coefficient, a measure of whether one variable is statistically dependent on another variable. If the absolute value of the Spearman coefficient is close to 1 , the two variables are more likely to have the same sign. Secondly, the study uses the Pearson coefficient, which has the value of 1 or -1 if there is total linear dependence between two variables. In particular, the Spearman coefficient of Weirwood storage between the simulation model and the reference model is 0.89 and the Pearson coefficient is $0 \cdot 84$. Both models identified the 1921/1922 drought as the most serious drought event of the time series. A comparison example of the specific reservoir state is depicted in Figure 3, which compares the reference model and the optimisation model.

Overall, the three models show structural uncertainty by using different algorithms and optimisation/simulation mode. These differences can contribute to the different supply deficit in each model (Table 3). A contributing factor is the network specification of each model, as the reference model is constrained by transfer capacity and has to rely on Weirwood in certain nodes; meanwhile, the simulation model and the optimisation model have a more relaxed constraint and therefore can be less dependent on Weirwood. The application of the control curve in each model also creates a slight discrepancy. Nevertheless, the control curve was left in the optimisation model because planning was done in prescriptive mode and the control curve would help preserve reservoir storage. As such, they can highlight potential

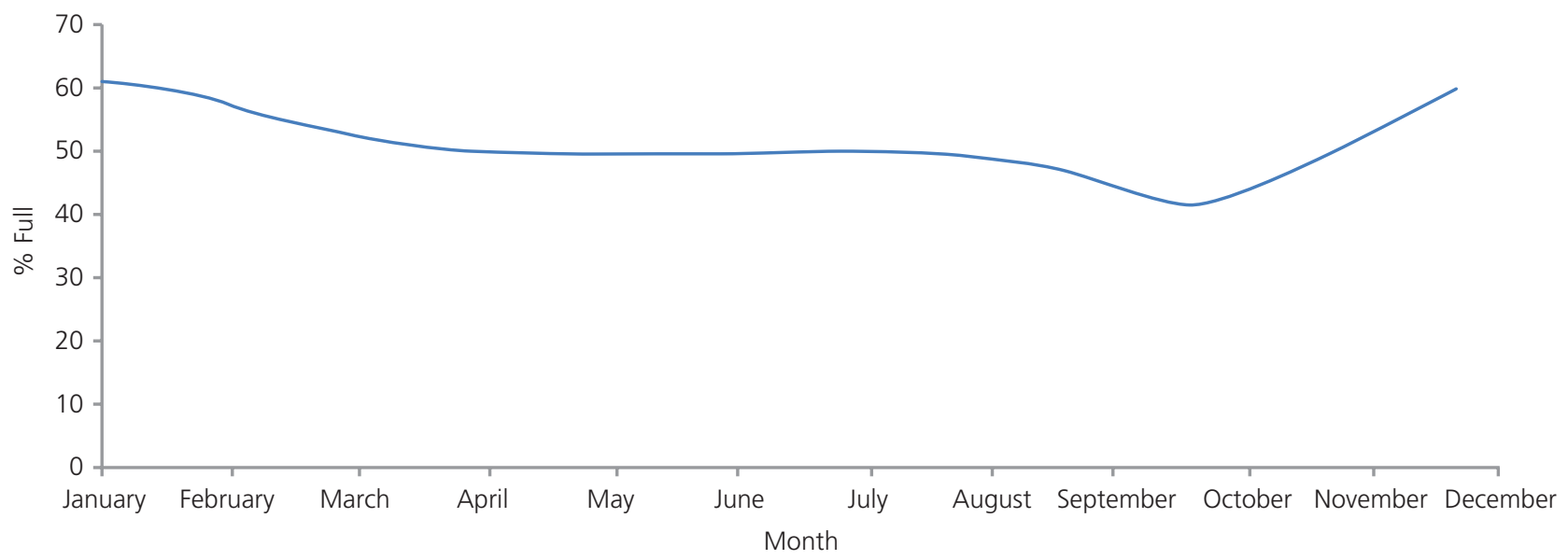

Figure 2. Example of a reservoir control curve, extracted from

Drought Plan, 2008 (Southern Water, 2008) 


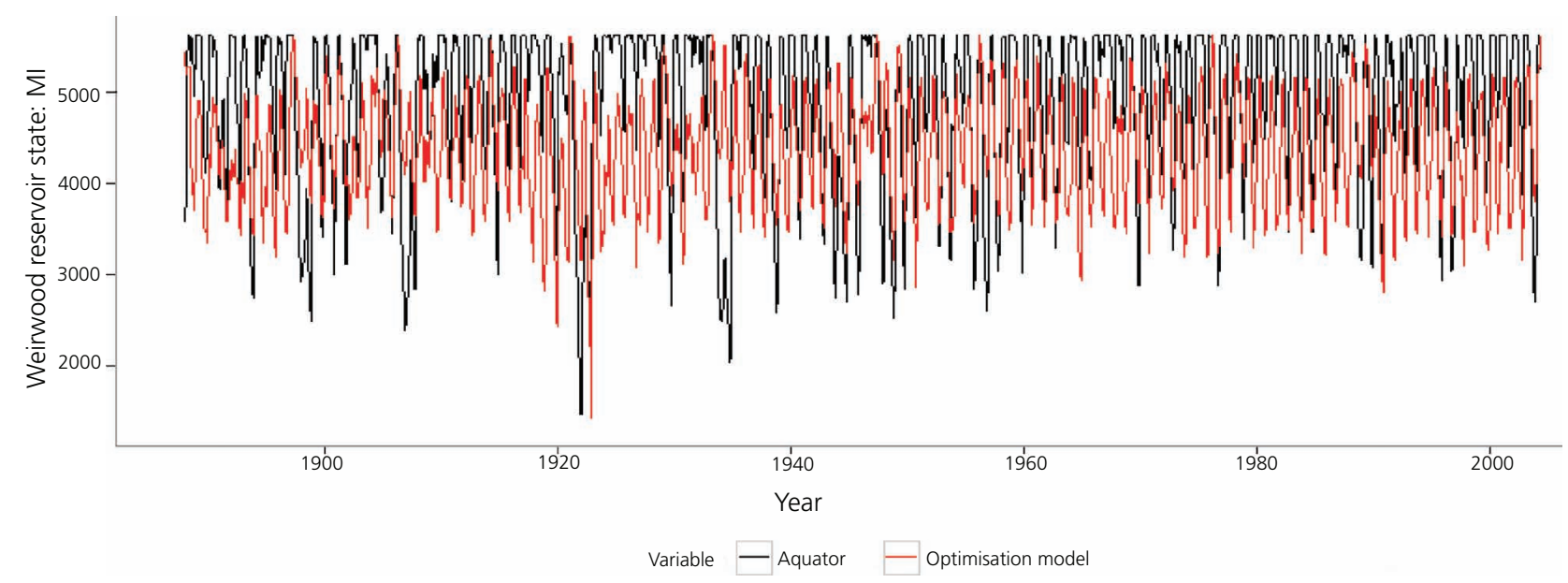

Figure 3. Comparison of the reference against the optimisation model if the control curve is applied only during high flows

vulnerabilities as well as potential opportunities of efficient water allocation.

\subsection{Vulnerability analysis}

\subsubsection{Simulation model results}

The simulation model confirms that the Sussex water system was sensitive to drought conditions of 1975-1976 and 1921-1922. If tested against the whole time series from 1888 to 2005 , the drought period that brought the worst supply deficit was the 1921-1922 period. Otherwise, for a shorter time series of 1961 onwards, the 1975-1976 drought was the most serious drought. The results indicate that the water system was well insured against the 1976 drought type, which was probably due to the current practice of using the worst historical drought as the design event in water resource and drought planning. Yet the results also indicate that the system is not immune to deficit risks due to demand growth, specifically under the Market Forces demand scenario. If demand jumps by $35 \%$ from the 2007 level, supply deficit will be ubiquitous in the 2050 s and every single year might be at a $60 \%$ daily risk of water supply deficit if no new measures are put in place.

Among the demand scenarios in the 2050s, only the most sustainability-oriented scenario (Sustainable Behaviour) could reduce mean supply deficit to a level lower than the 2020s/2030s level (Figure 4). The results were set up to flag when a deficit occurs. When there are surplus years, such occurrences are recorded as 0 deficit. The Innovation scenario, the sustainabilityled governance and individualistic consumption, meanwhile appear to be a neutral scenario compared to the 2020s and 2030s period. In the Local Resilience scenario, which is without sustainability-oriented governance, the projections show that, even if each individual exhibits environmental awareness and behaves responsibly, the water system still becomes less sustainable due to the overall demand increases. Finally, Market Forces - the most

Simulation model

Optimisation model

Factors reducing Assumption of total system connectivity

deficits

No reservoir control curve so can empty out reservoir to abate supply deficits

\section{Factors increasing Simulation mode \\ deficits}

Daily time step - can be subject to severe shortage at a daily time scale

\section{Optimisation mode}

Reservoir storage and annual groundwater licenses can be optimised with regard to the inflows and demand time series

Coarse time step

Constraints on link capacity

Reservoir control curve can prevent water release

Table 3. Contributing factors to the reduction and increase of supply deficit in each model 


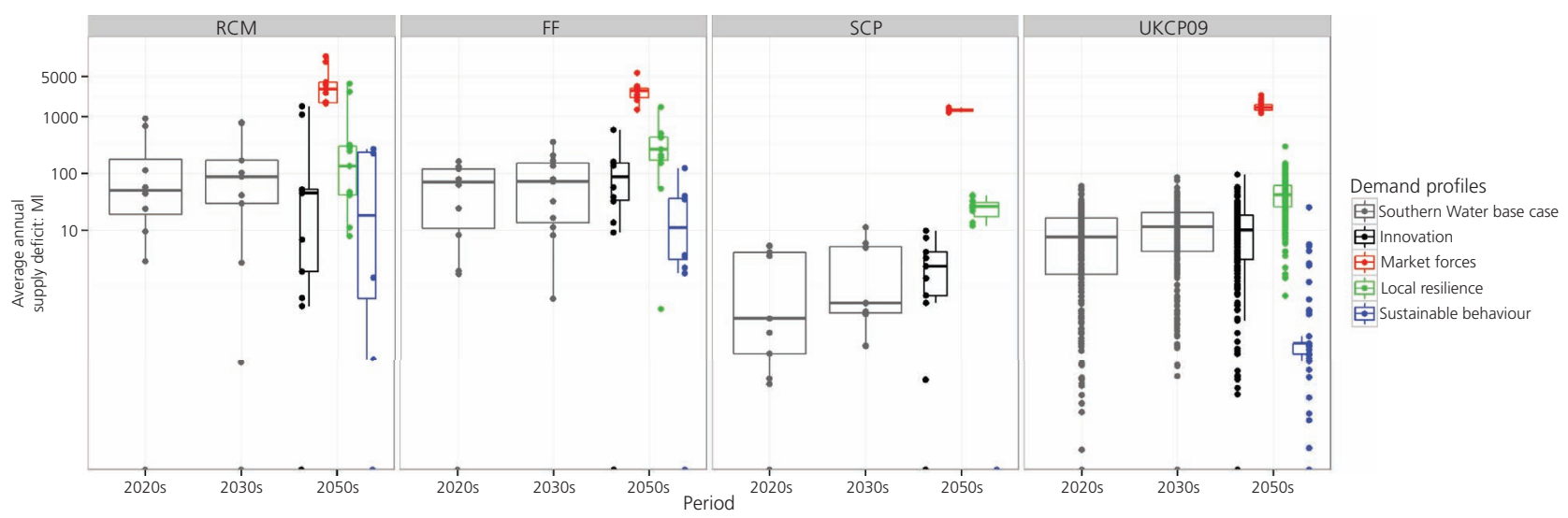

Figure 4. Average annual supply deficit (in megalitres) in North Sussex, Worthing and Brighton in the 2020s, 2030s and 2050s periods according to different climate and socio-economic scenarios using the simulation model. The dots represent the deficit in each ensemble member/scenario of each climate product. The box plots at the background are provided for reference of the median and other statistics extreme scenario in which both individual consumers and policy makers do not care for sustainability - poses a significantly high risk of system failures. In this socio-economic scenario, even under the mildest climate change prospect (projected by the SCP climate product), the system will experience high supply deficit. The UKCP09 climate product leads to a similar but wider range of supply deficit compared to SCP, while RCM and FF show more serious conditions that lead to high frequencies of failures.

\subsubsection{Optimisation model results}

Similar to the simulation model, the optimisation model shows that the different climate products and socio-economic scenarios can vary the projections of annual supply deficits by up to $10000 \mathrm{Ml}$ (Figure 5). Optimisation model results demonstrate that demand uncertainty is significant in 2050s. Aside from the Market Forces scenario, the Local Resilience scenario poses a slightly higher deficit risk compared to the Innovation and the Sustainable Behaviour scenarios. The optimisation model further shows that smart supply allocation can potentially alleviate water supply deficit. In practice, the model results are, however, the minimum possible deficit, since such efficient supply allocation requires perfect information (prior to the decision) of the climate conditions and drought sequences.

Nevertheless, the Market Forces scenario is the failure threshold of the system, in which the system fails in all 2050s climate conditions. Moreover, in terms of environmental flows in the River Rother, except for the RCM group, the river flows may frequently fall below the current minimum environmental flows. This reflects the risks of drier river states and the reducing supply capacity of the Rother to the Sussex water supply system. Despite

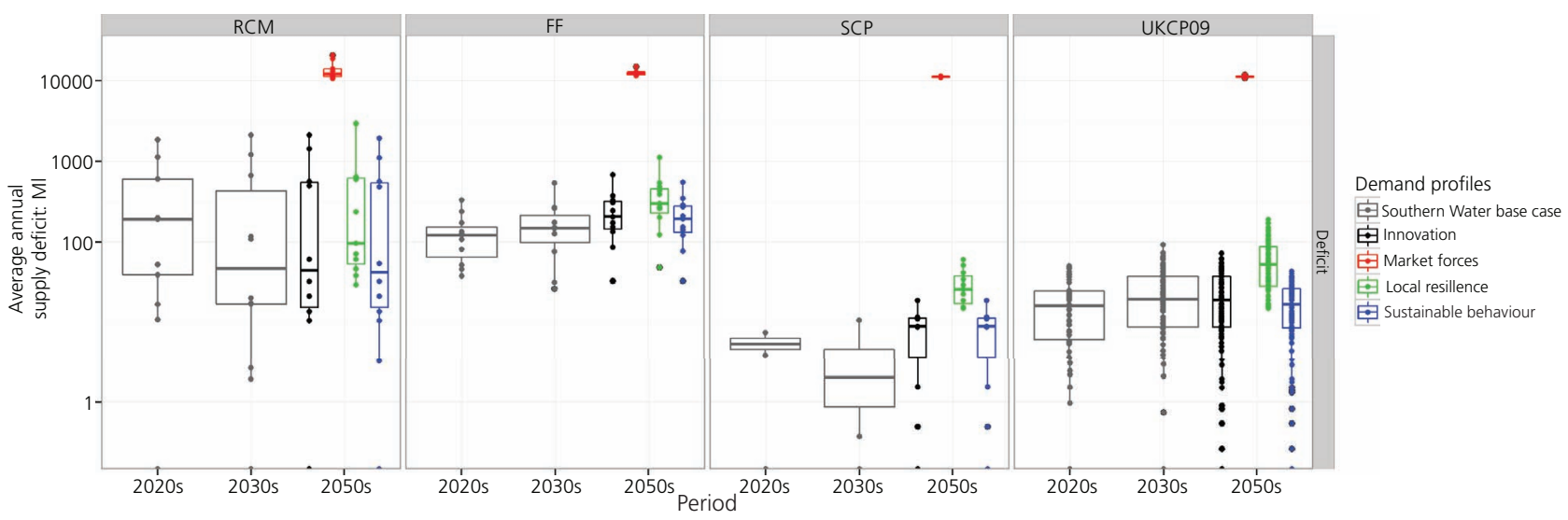

Figure 5. Average annual supply deficit (in megalitres) in North Sussex, Worthing and Brighton in the 2020s, 2030s and 2050s periods according to different climate and socio-economic scenarios using the optimisation model. The dots represent the deficit in each ensemble member/scenario of each climate product. The box plots at the background are provided for reference of the median and other statistics 
the slight variation in the cost of alternative sources, the overall cost is mostly influenced by the water demand level and remains relatively stable across the climate products.

Optimisation model results further indicate potential locations of water supply deficits. Overall, within the 2020s and the 2030s, deficit occurs only in the North Sussex area. Aside from the intercompany transfer and the environmental flow deficits in Rother and Weirwood, deficit in other nodes appear to be negligible. Model results depict the heterogeneous distribution of risks on the network according to the different climate products. Overall, RCM and FF climate conditions will lead to more severe deficits, while the SCP group rarely leads to any deficit or system failures. However, in three North Sussex nodes, the risks across the climate product are similar, while in another node, the risk by RCM conditions is higher than the FF and UKCP09 conditions.

The socio-economic scenarios of the 2050s show further impacts on the study area under different demand profiles. The deficit mainly occurs in the North Sussex area, because the Worthing and Brighton areas are more reliant on groundwater, and, in this model, are less likely to be affected by changes in surface water supply from the River Rother and the River Medway (Weirwood reservoir). The Market Forces scenario, however, shows that with extreme water demand, the Brighton area might experience water deficit under all climate conditions. Network analysis further demonstrates that under such situation, the nodes with fewer accesses to alternative supplying sources are likely to fail. In the case of the Market Forces scenario, each region of the study area will also become highly localised in its supply, as there is little spare capacity to transfer water to other regions.

\section{Implications of model choice and structural uncertainty in vulnerability analysis}

Overall, the comparative usage of a simulation model and an optimisation model in this study shows that using one of the two might highlight different features and vulnerability of the water system. The simulation model highlights potential vulnerability if the current operational practice is applied in the future. On the other hand, the optimisation model shows the vulnerability of the current system under the best possible operation. As shown in Section 3, the current Sussex water resources zone could be more resilient to water deficit risks if certain improvements in reservoir control rule are implemented. However, ultimately, the system still needs to undergo structural changes to enhance system capacity to cope with future higher demand and climate risks.

In terms of vulnerability indicated, simulation results show specific drought types and conditions that could lead to failure. They thus emphasise that new drought types as projected in the RCM and FF climate products could be dangerous to the water system, which still performs well under variations of the historic extreme droughts. Optimisation results meanwhile identify failure risk factors that go beyond operational ones, failure risks that threaten the most optimised systems. Therefore, their different structures help highlight whether operational practice or inherent supply/ demand vulnerability are the key risks of failure. Through a conjunctive use of both a simulation and an optimisation model, the study depicts that the current system could be vulnerable to climate change and demand growth both under the current practice and under the best-case scenario. As such, using solely a simulation model or an optimisation model can orientate adaptation decisions towards improving operational practices or enhancing current infrastructure. A simulation model can demonstrate that the system is vulnerable, while an optimisation model can explore if there are any options or operational improvements that reduce system vulnerability. On the other hand, an overoptimised system can fail to consider uncertainty and therefore shows unrealistic performance that is possible only under perfect knowledge of climate and water demand changes. The study therefore shows the impact of modelling choices and model structural uncertainty on vulnerability analysis of climate change impacts.

Risk factors highlighted in the study include climate risks as projected by different climate products and socio-economic scenarios. Study results further demonstrate that water demand is quickly becoming a controlling factor once it increases by more than $35 \%$ from the 2007 water demand level. Both models show a gradual increasing risk of supply deficit in the 2020s and the 2030s. Water deficit risks vary widely in the 2050s and are highly dependent on the socio-economic scenarios of the area.

The study also illustrates the wide uncertainty within climate and socio-economic scenarios. In essence, the four different climate products of RCM, SCP, UKCP09 and FF project various levels of risks. They do not produce the same range of risks and, instead, consistently project a mild range of risks (e.g. SCP) to medium but diverse range risks (UKCP09) to a range of more severe risks (FF and RCM). Therefore, the number of scenarios being tested might not be a good indication of how wide the range of risks is. In essence, UKCP09 has a high number of scenarios but appears to project comparable or less severe risks to ensembles of fewer members such as FF and RCM.

\section{Conclusion}

In conclusion, the study has explored the potential implications of model choice and structural uncertainty on system vulnerability. It shows that, while both optimisation and the simulation models perform relatively well compared to the reference model of the managing water company, they indicate different risk factors. The simulation model shows that the current system is vulnerable to new drought sequences that are different to the historical ones, while the optimisation model identifies structural limitations in the supply network that are susceptible to water deficits.

Overall, while climate uncertainty is still a significant influence, water demand is quickly becoming a controlling factor once the 2007 demand level increases past the 35\% threshold. Both models demonstrate a gradual increasing risk of supply deficit in the 2020s 
Engineering Sustainability

Volume 170 Issue ES4
Water resource vulnerability: simulation

and optimisation models

Hoang and Dessai and the 2030s; the risks vary widely in the 2050s and are highly dependent on the socio-economic scenarios. The model shows that in order to avoid frequent supply failures in the 2050s, it is essential to maintain or lower the demand profile. The socio-economic scenarios indicate that such reservation can occur only under sustainability-led governance or socially responsible consumerism (such as the Innovation or Local Resilience scenarios). The future failure risks are mainly distributed within the North Sussex area, with the exception of the Market Forces scenario.

\section{Acknowledgements}

The authors thank Southern Water and Atkins Ltd for providing support and data for the project. This study was funded by the UK's Engineering and Physical Sciences Research Council grant EP/G061181/1 - Adaptation and Resilience to Climate Change (ARCC) Water Project. Suraje Dessai acknowledges support from the UK Natural Environment Research Council (NE/H003509/1) and the European Research Council under the European Union's Seventh Framework Programme (FP7/2007 2013)/ERC Grant agreement number 284369 .

\section{REFERENCES}

Alcamo J and Henrichs T (2002) Critical regions: a model-based estimation of world water resources sensitive to global changes. Aquatic Sciences 64(4): 352-362.

Arnell NW (1999) Climate change and global water resources. Global Environmental Change 9(Supplement 1): S31-S49, http://www.sciencedirect.com/science/article/pii/ S0959378099000175.

Arnell NW and Charlton MB (2009) Adapting to the effects of climate change on water supply reliability. In Adapting to Climate Change: Thresholds, Values, Governance. Cambridge University Press, pp. 42-53.

Atkins (2009) Sussex Aquator Model Description, internal note.

Bell V, Kay A, Cole S et al. (2012) How might climate change affect river flows across the Thames basin? An area-wide analysis using the UKCP09 regional climate model ensemble. Journal of Hydrology 442(2012): 89-104.

Berkhout F and Hertin J (2002) Foresight futures scenarios: developing and applying a participative strategic planning tool. Greener Management International (37): 37-52.

Beven K (2009) Environmental Modelling: an Uncertain Future? CRC Press, Boca Raton, FL, USA.

British Geological Survey (2012) Digital Geological Map Data of Great Britain - 10k (DiGMapGB-10) Artificial version 2. Nottingham, UK.

Cave M (2009) Independent Review of Competition and Innovation in Water Markets: Final Report. Department for Environment, Food and Rural Affairs, London, UK.

Chun K, Wheater H and Onof C (2013) Comparison of drought projections using two UK weather generators. Hydrological Sciences Journal 58(2): 1-15.

Downing TE, Butterfield RE, Edmonds B et al. (2003) Climate Change and the Demand for Water: Research Report. Stockholm Environment Institute Oxford Office, Oxford, UK.
EA (Environment Agency) (2008) Water: Planning Ahead for an Uncertain Future - Water in the 2050s. EA, Bristol, UK.

Fowler H, Kilsby C and O'Connell P (2003) Modeling the impacts of climatic change and variability on the reliability, resilience, and vulnerability of a water resource system. Water Resources Research 39(8): 1222.

Gan TY (2000) Reducing vulnerability of water resources of Canadian prairies to potential droughts and possible climatic warming. Water Resources Management 14(2): 111-135.

Jain S, Woodhouse CA and Hoerling MP (2002) Multidecadal streamflow regimes in the interior western United States: implications for the vulnerability of water resources. Geophysical Research Letters 29(21): 32-1-32-4.

Kasprzyk JR, Nataraj S, Reed PM and Lempert RJ (2013) Many objective robust decision making for complex environmental systems undergoing change. Environmental Modelling and Software 42: 55-71.

Lopez A, Fung F, New M et al. (2009) From climate model ensembles to climate change impacts and adaptation: a case study of water resource management in the southwest of England. Water Resources Research 45(8): W08419.

Loucks DP and Van Beek E (2005) Water Resources Systems Planning and Management: an Introduction to Methods, Modes, and Applications. United Nations Educational, Scientific and Cultural Organization, Paris, France.

Matrosov ES, Padula S and Harou JJ (2013a) Selecting portfolios of water supply and demand management strategies under uncertainty - contrasting economic optimisation and 'robust decision making' approaches. Water Resources Management 27(4): 1123-1148.

Matrosov ES, Huskova I, Kasprzyk JR, Harou JJ and Reed PM (2013b) A many-objective optimization of supply and demand management options for the Thames basin. EGU General Assembly Conference Abstracts, p. 11310.

Murphy J, Sexton D, Jenkins G et al. (2010) Climate change projections for the UK (UKCP09). American Geophysical Union, Fall Meeting 2010.

Oki T and Kanae S (2006) Global hydrological cycles and world water resources. Science 313(5790): 1068-1072.

Oudin L, Hervieu F, Michel C et al. (2005) Which potential evapotranspiration input for a lumped rainfall-runoff model?: Part 2 - towards a simple and efficient potential evapotranspiration model for rainfall-runoff modelling. Journal of Hydrology 303(1): 290-306.

Parson E, Burkett V, Fisher-Vanden K et al. (2007) GlobalChange Scenarios: Their Development and Use. US Department of Energy, Washington, DC, USA, US Department of Energy Publications 7.

Prudhomme C, Young A, Watts G et al. (2012) The drying up of Britain? A national estimate of changes in seasonal river flows from 11 regional climate model simulations. Hydrological Processes 26(7): 1115-1118.

Southern Water (2008) Drought Plan: Planning Report. Southern Water, West Sussex, UK. 
Engineering Sustainability

Volume 170 Issue ES4
Water resource vulnerability: simulation

and optimisation models

Hoang and Dessai
Southern Water (2009) Water Resources Management Plan: Planning Report. Southern Water, West Sussex, UK.

SPRU (Science Policy Research Unit) (2002) Foresight Futures: 2020 Revised Scenarios and Guidance. SPRU, University of Sussex, Brighton, UK.

Vörösmarty CJ, Green P, Salisbury J and Lammers RB (2000) Global water resources: vulnerability from climate change and population growth. Science 289(5477): 284.

Wade SD (2005) Sussex Model Note. Atkins Ltd, Epsom, UK.

Wade SD, Rance J and Reynard N (2013) The UK climate change risk assessment 2012: assessing the impacts on water resources to inform policy makers. Water Resources Management 27(4): 1085-1109.
Weaver CP, Lempert RJ, Brown C et al. (2013) Improving the contribution of climate model information to decision making: the value and demands of robust decision frameworks. Wiley Interdisciplinary Reviews: Climate Change 4(1): 39-60.

Wilby RL (2005) Uncertainty in water resource model parameters used for climate change impact assessment. Hydrological Processes 19: 3201-3219, http://dx.doi.org/10. 1002/hyp.5819.

Wilby RL and Harris I (2006) A framework for assessing uncertainties in climate change impacts: low-flow scenarios for the River Thames, UK. Water Resource Research 42: W02419, http://dx.doi.org/10.1029/2005WR004065.

\section{HOW CAN YOU CONTRIBUTE?}

To discuss this paper, please email up to 500 words to the editor at journals@ice.org.uk. Your contribution will be forwarded to the author(s) for a reply and, if considered appropriate by the editorial board, it will be published as discussion in a future issue of the journal.

Proceedings journals rely entirely on contributions from the civil engineering profession (and allied disciplines). Information about how to submit your paper online is available at www.icevirtuallibrary.com/page/authors, where you will also find detailed author guidelines. 